\title{
La dimensión práctica del saber erótico de Sócrates
}

\author{
LuCAS SOARES \\ Universidad de Buenos Aires \\ Argentina
}

RESUMEN. ¿Qué es lo que puntualmente sabe Sócrates acerca del amor? ¿Qué dimensiones compromete tal tipo de saber erótico? ¿Cómo se presenta a sí mismo en relación con el amor alguien que al término de su discurso afirma que se ejercita especialmente en los asuntos amorosos e incita a otros a hacerlo (Smp. 212b5-7)? Tales son las preguntas que me propongo desarrollar en el presente trabajo, partiendo de una serie de pasajes tomados de diálogos platónicos tempranos y de transición, y de la Memorabilia y el Banquete de Jenofonte, pasajes a través de los cuales procuro examinar, por un lado, la dimensión práctica (áskēsis) comprometida en el saber erótico de Sócrates y, por otro, su vinculación con la dimensión teorética de tal saber cuando éste apunta hacia la Idea de belleza del Banquete.

Palabras Clave. Éros; saber; áskēsis; joven; belleza.

Ante la propuesta de Erixímaco de encomiar al dios Éros, Sócrates confiesa en el Banquete que él se encuentra en óptimas condiciones para elogiarlo dado que, tras haber aprendido en su momento las lecciones de Diotima, no sabe (epístasthai) acerca de otra cosa que de asuntos eróticos (tà erōtiká, Smp. 177d6-e3). ${ }^{1}$ Esta declaración no debería llamarnos la atención si no viniera de alguien que justamente encontró en la profesión de ignorancia su tono filosófico, tal como, entre otros pasajes del corpus platónico, se lee en la Apología, donde Sócrates interpreta el célebre mensaje oracular relativo a su sabiduría señalando que él es el más sabio de entre todos los hombre por cuanto advierte que en lo que respecta a la sabiduría no vale en verdad nada ( $A p$. 23a3-b4); y asimismo en el testimonio que nos brinda Aristóteles en Refutaciones sofísticas, según el cual Sócrates

Email:1ucso74@gmail.com

Doctor en Filosofía - Facultad de Filosofía y Letras de la Universidad de Buenos Aires.

Investigador Adjunto del Consejo Nacional de Investigaciones Científicas y Técnicas (CONICET)

${ }^{1}$ Véase en la misma línea Jenofonte, Mem. II, 6, 28, donde Sócrates reconoce ser un entendido en cosas de amor. 
siempre adoptaba el papel del que pregunta, jamás del que contesta, pues confesaba que no sabía nada (SE 183b7-8).

La pregunta que surge ante la confesión socrática del Banquete sería entonces: ¿qué es lo que puntualmente sabe el Sócrates platónico² acerca del amor? ¿Qué dimensiones se hallan implicadas en tal tipo de saber erótico? ¿Cómo se presenta a sí mismo en relación con el amor alguien que al término de su discurso afirma que se ejercita (askeîn) especialmente en los asuntos amorosos e incita a otros a hacerlo (Smp. 212b5-7)? Tales son las preguntas que me propongo desarrollar en el presente trabajo, partiendo de una serie de pasajes tomados de diálogos platónicos tempranos y de transición, y de la Memorabilia y el Banquete de Jenofonte; pasajes a través de los cuales procuro examinar, por un lado, la dimensión práctica (áskēsis) comprometida en el saber erótico socrático. Esta dimensión nos va a revelar que Sócrates, cuando se ve atraído, no por la Idea de belleza que corona la iniciación erótica propuesta por Diotima en el Banquete, sino por la belleza de los jóvenes distinguidos que conformar su sistema orbital, se halla atravesado por una serie de tensiones eróticas que permite relativizar (en parte) la imagen cristalizada que conservamos de aquél como la encarnación misma de la continencia en materia amorosa (de allí que la sacerdotisa señale casi al término de su discurso que si alguna vez Sócrates llegara a aprehender lo Bello en sí, aquello le parecerá que no es como los jóvenes ante los que suele quedarse estupefacto, Smp. 211d3-8). Por otro lado, me interesa preguntarme aquí por la posibilidad

\footnotetext{
${ }^{2}$ Sobre el antiguo y espinoso problema acerca de la distinción entre el Sócrates histórico y el Sócrates platónico, cf., entre otros, V. De Magalhâes-Vilhena, Le problème de Socrate. Le Socrate historique et le Socrate de Platon, París, Presses Universitaires de France, 1952, pp. 186-193, 354-451; y M. CAnto-Sperber (ed.), Filosofía griega, Buenos Aires, Docencia, vol. I, 2000, pp. 217, quien acertadamente señala al respecto: "Felizmente, las violentas querellas que agitaron el mundo de los historiadores de la filosofía griega respecto de la parte correspondiente al socratismo en el pensamiento platónico se han apaciguado un poco en el curso de los últimos decenios; sobre todo, ninguna de las posiciones extremas que se acaban de recordar (según las cuales Platón debería todo a Sócrates o, por el contrario, no le debería nada) se toman hoy en serio. Se admite que el pensamiento platónico no se confunde con el pensamiento socrático, al mismo tiempo que se reconoce la presencia de una influencia socrática en los primeros escritos de Platón". En lo que toca a nuestro análisis, cuando hablamos de Sócrates nos referimos principalmente al Sócrates platónico (salvo cuando aclaremos que se trata del Sócrates de Jenofonte), o - para decirlo en palabras de F. Nietzsche, Más allá del bien y del mal, Madrid, Alianza, 1983 [1885], p. 120 - a Sócrates como "máscara" o "personaje conceptual” del platonismo. Véase en esta línea de análisis J. Derrida, La tarjeta postal. De Sócrates a Freudy más allá, México, Siglo XXI, 1986, pp. 18, 20-21; G. Deleuze - F. Guattari, ¿Qué es la filosofía?, Barcelona, Anagrama, 1993, pp. 64-67; y P. НAdot, Elogio de Sócrates, Barcelona, Paidós, 2008, pp. 9-10.
} 
de vinculación entre la dimensión práctica del saber erótico de Sócrates y la dimensión teorética de tal saber cuando éste se orienta hacia la Idea de belleza del Banquete.

La atracción de Sócrates, asiduo visitante de los gimnasios de Atenas, ${ }^{3}$ por los muchachos y el magnetismo erótico que, a pesar de su silénica fealdad ("resulta significativo -apunta Nietzsche- que sea Sócrates el primer gran heleno que fue feo"4), el filósofo despertaba en ellos es un tópico reiterado en los diálogos platónicos tempranos, una de cuyas escenas más repetidas nos lo muestra declarando su amor por alguno de los jóvenes que despuntara socialmente por su kalokagathía (como, por ejemplo, Alcibíades, Cármides, etc.). ${ }^{5}$ Recordemos al respecto las elocuentes palabras del joven Fedro en el Banquete:

Querido Agatón, si respondes a Sócrates, ya no le importará nada de qué manera se realice cualquiera de nuestros proyectos actuales, con tal que tenga sólo a uno con quien pueda dialogar, especialmente si es bello (Smp. 194d1-4). ${ }^{6}$

Un indicio del saber erótico que Sócrates reconoce tener al comienzo del Banquete se deja entrever en el Lisis, donde el filósofo afirma ante Hipotales, un enamorado del joven que da título a este diálogo de juventud,

${ }^{3}$ Dover señala que el gimnasio y la palestra ofrecían muchas oportunidades de ver desnudos a los jóvenes y funcionaban como centros sociales en los que era posible establecer algún contacto (K.J. Dover, Greek Homosexuality, Cambridge, Harvard University Press, 1978, pp. 54-55). Para una caracterización general de la paiderastía en la Grecia arcaica y clásica, cf. especialmente L. Brisson, "Agathon, Pausanias, and Diotima in Plato's Symposium: Paiderastia and Philosophia", in J.H. Lesher - D. Nails - F.C.C. Sheffield, Plato's Symposium: Issues in Interpretation and Reception, Washington, DC, Center for Hellenic Studies, 2006, pp. 230-235.

${ }^{4}$ F. Nietzsche, "Sócrates y la tragedia", en El nacimiento de la tragedia, Madrid, Alianza, 1973 [1972], p. 225.

${ }^{5}$ Sobre el tema de la presencia de la homosexualidad masculina en los textos platónicos, cf. especialmente T. Menissier, Eros Philosophe. Une interprétation philosophique du Banquet de Platon, Paris, Kimé, 1996, pp. 71-74.

${ }^{6}$ Para los pasajes platónicos citados seguimos la edición de J. Burnet, Platonis Opera, Oxford, Clarendon Press, 5 vols., 1900-1907 (vol. I: E.A. Duke et alia, 1995; S.R SuIngS, Platonis Rempublican, Oxford, Oxford University Press, 2003). Del Banquete tuvimos en cuenta las siguientes ediciones: R.G. Bury, The Symposium of Plato, Cambridge, W. Heffer and Sons, 1932; K.J. Dover, Plato, Symposium, Cambridge, Cambridge University Press, 1980; Сн. Rowe, Plato, Symposium, Warminster, Aris \& Phillips Ltd. 1998; y las traducciones castellanas de M. Martínez Hernández, Platón, Banquete, en Diálogos, Madrid, Gredos, 1986, vol. III; V. Juliá, Platón, Banquete, Buenos Aires, Losada, 2004; y C. Mársico, Platón, Banquete, Buenos Aires, Miluno, 2009. 
que por gracia divina detenta una cierta facilidad de conocer al que ama y al que es amado (Ly. 204b8-c2).

Por su parte Jenofonte también da cuenta en su Banquete de la disposición erótica que Sócrates pone en escena a la hora de vincularse con los jóvenes bellos, disposición que justifica en dicha obra la necesidad de encomiar a Éros:

Por mi parte, no podría decir momento alguno en el que no esté enamorado de alguien, y Cármides, aquí presente, se que ha tenido muchos amantes y que él mismo se ha apasionado por alguno de ellos (Smp. VIII 2 1-4).

Esta disposición erótica del Sócrates de Jenofonte encuentra su correlato exacto en el Sócrates de Platón, quien en el Cármides le hace decir al filósofo: "En relación con bellos adolescentes soy un "cordel blanco", porque casi todos, en esta edad, me parecen hermosos" (Chrm. 154b8-10). ${ }^{8} \mathrm{Al}$ inicio de este diálogo temprano leemos uno de los pasajes más audaces que atenta contra la supuesta continencia socrática en materia erótica. Allí Platón describe con precisión el impacto que le produjo a Sócrates el encuentro con Cármides, adolescente ante cuya belleza los jóvenes y hombres maduros quedaban extasiados como si estuvieran frente a la imagen de un dios:

Entonces ocurrió, querido amigo, que me encontré como sin salida, tambaleándose mi antigua audacia (thrasýtess); esa audacia que, en otra ocasión, me habría llevado a hacerle hablar fácilmente. Pero después de que me miró con ojos que no sé qué querían decir y se lanzaba ya a preguntarme, y todos los que estaban en la palestra nos cerraban en círculo, entonces, noble amigo, intuí lo que había dentro del manto y me sentí arder y estaba como fuera de mí, y pensé que Cidias sabía mucho en cosas del amor, cuando, refiriéndose a un joven hermoso, aconseja a otro que "si un cervatillo llega frente a un león, ha de cuidar de no ser hecho pedazos". Como si fuera yo mismo el que estuvo en las garras de esa fiera, cuando me preguntó si sabía el remedio para la cabeza, a duras penas le pude responder que lo sabía (Chrm. 155c5-e3).

\footnotetext{
${ }^{7}$ Seguimos la traducción castellana de J. Zaragoza, Jenofonte: Recuerdos de Sócrates, Banquete, Apología de Sócrates, Madrid, Gredos, 1993.

${ }^{8}$ Seguimos, con una leve modificación, la traducción castellana de E. Lledó, Cármides, en Platón, Diálogos, Madrid, Gredos, 1981, vol. I.
} 
Tanto en el Menéxeno de Platón como en el Banquete de Jenofonte encontramos otras dos muestras similares de pérdida socrática del aplomo erótico. En el primer diálogo, requerido por Menéxeno, un joven de dieciocho años interesado por la oratoria, Sócrates afirma:

Pero tal vez te burles de mí, si, viejo como soy, te produzco la impresión de que aún jugueteo como un niño (òn éti paízein). (...) Pues bien, sin duda debo complacerte; hasta el punto de que incluso si me pidieras que me quitase el manto y danzara, casi te haría el gusto, puesto que estamos solos (Mx. 236c8-d2). ${ }^{9}$

En la segunda obra, ante la extraña propuesta socrática de abstenerse de besar a los muchachos en la flor de la edad, el filósofo es desenmascarado por un Cármides ya maduro, así como en el Banquete platónico lo es por un Alcibíades también ya maduro:

Pero en realidad, Sócrates, ¿por qué agitas así ante tus amigos tales espantajos para alejarnos de los muchachos bellos, cuando yo te vi a ti mismo, por Apolo, un día que en la escuela ambos andaban buscando algo en el mismo libro, con tu cabeza apoyada en su cabeza y tu hombro desnudo en el hombro desnudo de Critobulo? (Smp. IV 27-28).

Ya sea en el Cármides como cervatillo; ya sea en el Menéxeno como niño, lo que se desprende de estos pasajes es que Sócrates siempre busca juguetear (paizein) con los jóvenes haciéndoles creer que son ellos los que, cual leones, lo cercan con su belleza y mandan sobre él en términos eróticos y dialógicos, controlando desde el inicio la situación. Es que en el fondo, como ya lo había percibido Nietzsche, Sócrates era un gran erotikós: "He dado a entender con qué cosas podía Sócrates causar repulsión: tanto más queda por aclarar que fascinaba. - Una razón es que él descubrió una especie nueva de agón , que en esto él fue el primer maestro de esgrima para los círculos aristocráticos de Atenas. Fascinaba en la medida en que removía el instinto agonal de los helenos, - introdujo una variante en la lucha pugilística entre los jóvenes y los adolescentes. Sócrates era también un gran erótico". ${ }^{10}$ Un claro caso de agón erótico, en el que Sócrates invierte la relación haciéndose pasar por esclavo de la tiranía ejercida por la belleza de un joven, se observa en el Menón; más puntualmente en la

${ }^{9}$ Seguimos la traducción castellana de E. Acosta, Menéxeno, en Platón, Diálogos, Madrid, Gredos, 1983, vol. II.

${ }^{10}$ F. Nietzsche, "El problema de Sócrates", en Crepúsculo de los ídolos, Madrid, Alianza, 1973 [1888], p. 47. 
respuesta que da Sócrates tras la segunda definición de la areté brindada por el joven protagonista, discípulo del sofista Gorgias:

¡Eres un desconsiderado, Menón! Sometes a un anciano a que te conteste estas cuestiones y tú no quieres recordar y decir qué afirmó Gorgias que es la virtud. Aun con los ojos vendados, Menón, cualquiera sabría, al dialogar contigo, que eres bello y que también tienes tus enamorados. Porque cuando hablas no haces otra cosa que mandar, como los niños consentidos, que proceden cual tiranos mientras les dura su encanto; y al mismo tiempo, habrás notado seguramente en mí que no resisto a los guapos. Te daré, pues, ese gusto y te contestaré (Men. 76a9-c2)."

Lo paradójico de este pasaje es que la dinámica de las conversaciones que Sócrates suele entablar con los jóvenes allegados a su círculo revela lo contrario: que toda la potencia del supuesto saber erótico de Sócrates reside justamente en su capacidad de resistencia frente a la "tiránica" seducción que sobre él ejercen los jóvenes bellos. Por allí discurre uno de los nervios centrales de su áskēsis erótica.

Esta capacidad de resistencia alcanza su clímax en Banquete, al punto de que Platón introduce allí al personaje de Alcibíades para, entre otras cosas, desenmascarar dicha capacidad y el sistema de poses que Sócrates suele adoptar cuando está frente a algún joven bello:

Veis, en efecto, que Sócrates está en disposición amorosa con los jóvenes bellos (erōtikôs diákeitai tôn kalôn), que siempre está en torno suyo y se queda extasiado, y que, por otra parte, ignora todo y nada sabe, al menos por su apariencia. (...) Pasa toda su vida ironizando y bromeando (eirōneuómenos kaì paízōn) con la gente (Smp. 216d2-4, e4-5). ${ }^{12}$

Otro de los nervios centrales de la áskēsis erótica socrática es el recurso de la ironía (eirōneía), entendida como "simulación" o "fingimiento", y cuya potencia se expresa sobre todo en el terreno dialéctico y el erótico; de aquí que algunos intérpretes lleguen a distinguir dos tipos de ironía: dialéctica y erótica. La primera se manifiesta mediante una tendencia discursiva que lleva a Sócrates a simular, a través del juego de preguntas y respuestas, la adopción del punto de vista del interlocutor, haciéndole creer así que le otorga la razón respecto del tema objeto de discusión. De

${ }^{11}$ Seguimos la traducción castellana de F.J. Olivieri, Menón, en Platón, Diálogos, Madrid, Gredos, 1983, vol. II.

${ }_{12}$ Véase, entre otros, НАdot, Elogio..., pp. 26-33, 49-54. 
modo análogo a la de tipo dialéctico (o discursivo), la ironía erótica revela la tendencia socrática de fingir enamoramiento con vistas a invertir su posición de amante (erastés) por la del objeto amado (erómenos) de los jóvenes (Smp. 222b3-4). Más allá de esta distinción de planos, ambos tipos de ironía implican la puesta en escena de un fingir autodespreciativo, es decir, de una actitud psicológica según la cual Sócrates procura a toda costa parecer inferior de lo que es, enmascarando lúdicamente las intenciones últimas que orientan su práctica dialógica con el fin de invertir los valores en juego en la discusión y en la relación erótica que mantiene con el joven de turno. ${ }^{13}$ Tal es justamente la autodesvalorización erótica que Alcibíades viene a desenmascarar -porque justamente uno de los rasgos característicos de la ironía pasa por el enmascaramiento- en algunos de los tramos centrales de su elogio de Sócrates (Smp. 222a7-b7), y la que -si tenemos en cuenta las semejanzas estructurales entre la figura socrática y el éros daímōn, hijo de Póros y Penía- termina por expresar Diotima en su discurso:

Pero, por otra parte, de acuerdo con la naturaleza de su padre, está al acecho de lo bello y de lo bueno; es valiente, audaz y activo, hábil cazador, siempre urdiendo alguna trama, ávido de sabiduría y rico en recursos, un amante del conocimiento a lo largo de toda su vida, un formidable mago, hechicero y sofista (thèreutès deinós, aei tinas plékōn mēkhanás, kai phronéseōs epithymētés kaì pórimos, philosophôn dià pantòs toû biou, deinòs góēs kaì pharmakeùs kaì sophistés, Smp. 203d4-8)

\footnotetext{
${ }^{13}$ Otros testimonios sobre la ironía socrática pueden verse, entre otros, en Platón, Ap. 38a1 ("no me creerán pensando que hablo irónicamente [ou peisesthé moi hōs eirōneuoménōi]"), R. I 337a4-7 (“¡Oh, Heracles! Aquí está Sócrates con su acostumbrada ironía [eiōthyîa eirōneía]; ya les había yo dicho a éstos que tú no querrías contestar, sino que fingirías [eirōneúsoio] y acudirías a todo antes que responder, si alguno te preguntaba"); Jenofonte, Mem. II, 6, 28-30; y Aristóteles, EN II 7, 1108a19-23 ("Pues bien, respecto de la verdad, al intermedio llamémosle veraz y veracidad a la disposición intermedia, y en cuanto a la pretensión, la exagerada, fanfarronería y el que la tiene, fanfarrón, y la que se empequeñece, disimulo, y disimulador [eirōneía kaì eírōn] el que lo tiene"), IV 7, 1127a22-23 ("el irónico [eírōn] niega lo que le pertenece o le quita importancia"). Para un análisis exhaustivo del testimonio platónico sobre la ironía socrática, así como también del de Aristófanes y Jenofonte, cf. especialmente G. Vlastos, "Socratic irony", in Socrates: Ironist and Moral Philosopher, Cambridge, Cambridge University Press, 1991, pp. 2342. Sobre la dimensión pedagógica de la ironía socrática, véase G.W.F. HEGEL, Lecciones sobre la historia de la filosofía, México, Fondo de Cultura Económica, 1955, pp. 52-56; y S. KierkegaArd, Sobre el concepto de ironía, en Escritos de Søren Kierkegaard, Madrid, Trotta, 2000, vol. I, p. 113, según el cual Sócrates fue el primero en introducir la ironía y en consagrarse a su práctica hasta el punto de sucumbir a ella.
} 
Para el momento dramático del Banquete, sabemos que Alcibíades y la filosofía son -si tenemos en cuenta el diálogo que mantiene con el personaje de Calicles en el Gorgias- los dos grandes amores opuestos que Sócrates confiesa tener (Grg. 481d1-5). En efecto, Platón contrasta en este diálogo de transición la impulsividad característica de su amado Alcibíades, quien cada vez dice algo distinto, con la pasividad y previsibilidad propias de la filosofía, que sostiene siempre lo mismo. No es casual en este sentido que en el Banquete Platón elija dar cuenta del amor de Sócrates por Alcibíades justo en el marco de las amenazas que éste impulsivamente le dirige al reconocerlo entre los asistentes del simposio:

Agatón, fijate si me vas a defender, porque mi amor por este hombre se volvió un tema no menor. De hecho, desde el momento en que me enamoré de él, ya no puedo ni mirar ni charlar con ningún hombre bello o él, muerto de celos y envidia por mí, hace cosas insólitas, me hace reclamos y apenas se aguanta de ir a las manos. Fijate, entonces, que no vaya a hacer algo así también ahora. Pacifícanos o, si intenta ponerse violento, defendeme, porque a mi la locura y la pasión fanática de éste me aterrorizan totalmente (Smp. 213c6-d6).

A partir del discurso de Alcibíades puede verse cómo, ante uno de los jóvenes más reputados de la época en términos de belleza, Sócrates, comportándose como un hábil cazador que siempre está urdiendo alguna trama, seduce y a la vez se encarga de frustrar la seducción que él mismo despliega a través de su áskēsis erótica; ${ }^{14}$ y asimismo cómo - dicho en términos nietzscheanos- en Sócrates "todo es exagerado, buffo, caricatura, todo es a la vez oculto, lleno de segundas intenciones, subterráneo". ${ }^{15}$ Porque una parte importante del saber práctico que el filósofo detenta en materia amorosa se asienta -como bien señala Foucault- en el principio que impide "ceder": "Pero lo que no saben, y lo que Alcibíades descubre en el

${ }^{14}$ Tal es la doble vertiente (positiva y negativa; atractiva y repulsiva; cómica y trágica) que exhibe la ironía socrática según Kierkegaard: "Pero precisamente porque es esencial a la ironía no desenmascararse jamás, y porque por otro lado le es igualmente esencial cambiar de máscara a la manera de Proteo, por eso debía necesariamente acarrear tanto dolor al mancebo enamorado. El ironista eleva al individuo por encima de su existencia inmediata, eso es lo liberador; pero luego le deja suspendido, como el sarcófago de Mahoma según la leyenda, entre dos imanes: lo atractivo y lo repulsivo. Si la ironía, por tanto, tiene algo de horroroso, tiene también algo de extraordinariamente seductor y encantador" (Sobre el concepto de ironía... p. 113).

${ }^{15}$ F. Nietzsche, "El problema de Sócrates", en Crepúsculo de los ídolos, Madrid, Alianza, 1973 [1888], p. 39; y НАDOт, Elogio..., p. 52. 
transcurso de la famosa 'prueba', es que Sócrates no es amado por ellos más que en la medida misma en que es capaz de resistir a su seducción, lo que no quiere decir que no sienta por ellos amor ni deseo, sino que se ve llevado por la fuerza del verdadero amor y que sabe verdaderamente amar a lo verdadero que hay que amar". ${ }^{16}$ Digamos que si en el marco de su iniciación erótica ante Sócrates Alcibíades está dispuesto a conquistarlo dándose, Sócrates emprende siempre el camino contrario: lo termina por conquistar sin darse. O, para ponerlo en términos de Lacan, si Sócrates no ama es porque sabe. ${ }^{17}$ Quizá esta estrategia del "conquistar sin darse" tenga que ver con aquello que Sócrates, haciendo gala de su saber erótico, le explica a su amigo Hipotales cuando éste acude a consultarle sobre sus fallidos cortejos al joven Lisis:

El que entiende de amores, querido, no ensalza al amado hasta que lo consigue, temiendo lo que pudiera resultar. Y, al mismo tiempo, los más bellos, cuando alguien los ensalza y alaba, se hinchan de orgullo y arrogancia. ¿No te parece? (Ly. 206a1-4). ${ }^{18}$

A partir del despliegue de su áskēsis erótica Sócrates es consciente de que si él conquistara dándose, los bellos jóvenes que son objeto de su búsqueda se hincharían de orgullo y de arrogancia, sin llegar a ser atrapados en su efectivo cortejo erótico-dialógico.

Pero así como Sócrates no encaja completamente en el modelo del racionalista griego a causa de su inclinación a tomar en serio los mensajes provenientes de los sueños, los oráculos y la voz interior del daímōn, ${ }^{19}$ a la luz de las tensiones eróticas motivadas por la belleza de los jóvenes podemos ver que tampoco termina por ajustarse al perfil ascético -y anticipadamente cristiano, como diría Nietzsche $-^{20}$ por el que el Sócrates

\footnotetext{
${ }^{16}$ M. Foucault, "El verdadero amor", en Historia de la sexualidad, México, Siglo XXI, 1984, vol. 2, p. 221.

${ }_{17}$ J. LaCAN, El seminario de Jacques Lacan. Libro 8: la transferencia, Buenos Aires, Paidós, 2003, p. 181.

${ }^{18}$ Seguimos la traducción castellana de E. Lledó, Lisis, en Platón, Diálogos, Madrid, Gredos, 1981, vol. I.

${ }^{19}$ Véase al respecto E.R. DodDs, Los griegos y lo irracional, Madrid, Alianza, 1980, pp. 176, 204. Para la aparición e influencia de esa señal demónica o voz divina que suele aparecérsele a Sócrates en diferentes fases de su vida y que siempre se le opone cuando está a punto de hacer algo incorrecto, cf., entre otros pasajes, $A p$. 31c8-d4, $R$. VI 496c3-5, Tht. 151a3-5; Jenofonte, Mem. IV 8.

${ }^{20}$ F. NieTzSChe, "Incursiones de un intempestivo", en Crepúsculo de los ídolos, Madrid, Alianza, 1973 [1888], p. 131: "Lo encuentro a Platón tan descarriado de todos los instintos fundamentales de los helenos, tan moralizado, tan cristiano anticipadamente. En la gran
} 
platónico es conocido en la historia de la filosofía. Aun cuando no deje de sorprender el hecho de que se haya podido enamorar de un personaje tan arrogante, ambicioso y pasional como Alcibíades, es justamente este amor (y también el profesado hacia otros jóvenes bellos) el que nos devuelve una imagen más rica y humana de Sócrates: la de alguien que puede llegar a sucumbir en su momento ante aquello que cree despreciar. Es interesante recordar al respecto un pasaje del Alcibiades I, donde pueden leerse los antecedentes de la relación erótica entre Sócrates y el joven político, cuyo desenlace relata Alcibíades en el Banquete bajo la figura del célebre rechazo socrático ("oro por bronce"):

Hijo de Clinias, creo que te sorprende que, después de haber sido yo el primero en enamorarme de ti, sea el único en no abandonarte cuando los demás lo han hecho, a pesar de que, mientras ellos te estuvieron importunando con su conversación, yo a lo largo de tantos años ni siquiera te dirigí la palabra. (...) Es por eso, estoy seguro, por lo que te preguntas sorprendido con qué idea no renuncio a mi amor y con qué esperanza me mantengo, cuando los demás ya han abandonado (Alc. I 103a1-c6). ${ }^{21}$

Sólo frente a la belleza física de Alcibíades el espíritu de Sócrates se siente realmente aturdido y hechizado. Alcibíades embota su entendimiento; hace vacilar toda su cultura. Como apunta al respecto Kristeva: "Notemos que en El banquete, Sócrates, visto por Alcibíades al final del diálogo, deja, a pesar de sus esfuerzos pedagógicos, la impresión absolutamente ambigua y carnavalesca de un sabio sospechoso que esconde bajo una apariencia seductora y libidinosa unas riquezas espirituales admirables, pero ambivalente cuando menos, turbador y sujeto a los desórdenes de la pasión. El verdadero ideal, el Sócrates ideal, es Diotima". ${ }^{22}$

Llegados hasta aquí, podemos concluir dos puntos. Por un lado, que el saber acerca del amor que Sócrates reconoce poseer en algunos de los pasajes platónicos y de Jenofonte traídos a colación, no se limita sólo a una vertiente teórica -ya sea en pos de que los jóvenes bellos se orienten hacia el cuidado del alma y la búsqueda de la areté, como en el caso de los diálogos tempranos y de transición; ya sea en pos de la Idea de belleza

fatalidad del cristianismo Platón es aquella ambigüedad y fascinación llamada el 'ideal'. ¡Y cuánto Platón continúa habiendo en el concepto de 'Iglesia', en la organización, en el sistema, en la praxis de la Iglesia!".

${ }^{21}$ Seguimos la traducción castellana de J. Zaragoza, Alcibíades I, en Platón, Diálogos, Madrid, Gredos, 1992, vol. VII.

${ }^{22}$ J. Kristeva, Historias de amor, México, Siglo XXI, 1987, p. 61. 
como en la fase madura del Banquete y el Fedro-, sino que presupone una importante áskēsis o dimensión práctica que podría definirse, tomando en préstamo una terminología del Sofista, como una técnica de la persuasión erótica (erōtiké tékhne ) o de la caza de hombres (théra anthrópon) llevada a cabo por los amantes de forma privada (Sph. 222d3-e3), y cuya meta apunta, como vimos, a hacerse desear por lo jóvenes; técnica por lo demás atribuida también a Sócrates por Jenofonte en su Memorabilia, donde vemos al filósofo aconsejar al bello Critobulo, quien se muestra ansioso por aprender todo lo relativo a la tékhnè de la caza de hombres de bien:

¡Ánimo, pues, Critobulo! Intenta ser bueno, y, cuando lo hayas conseguido, trata de cazar a los hombres de bien. Tal vez yo también podría ayudarte un poco en esta cacería por el hecho de que soy entendido en cosas de amor. Porque, cuando yo deseo a alguien, me lanzo todo entero con vehemencia, a fuerza de quererlos, a hacerme querer de ellos, a añorarles para ser añorado por ellos, a desear su compañía para que ellos deseen la mía. Veo que también tú necesitas tales artes cuando desees hacer amistad con alguien. Por ello, no me ocultes de quién querrías llegar a ser amigo, pues con el interés de agradar a quien me agrada creo que tengo experiencia para la caza de hombres. (Mem. II, 6, 28-30).

A partir de su experiencia en la caza erótica de jóvenes bellos, Sócrates sabe -y por tanto puede aconsejar, como lo hace con Hipotales en el Lisis- sobre lo que hay que decir o hacer para volverse grato y deseable a los ojos del amado. La práctica del cortejo (o del éros cazador) que supone la tékhnē erótica hace que Sócrates, tras invertir la relación pederástica al presentarse como amante y devenir el objeto amado, logre en un primer momento narcotizar (narkân, Men. 80a7) dialógicamente, como un "formidable mago, hechicero y sofista" (Smp. 203d8), a los jóvenes bellos en torno a su sistema órbital -así es como Menón, tras su fallida serie de definiciones sobre la areté, se siente una madeja de confusiones, hechizado y embrujado (goèteúeis kaì pharmátteis, Men. 80a2-3) por ese pez torpedo que representa Sócrates ${ }^{23}$-; y, en una segunda instancia, remover el instinto agonal de tales jóvenes mediante una serie de problematizaciones y "bellos discursos", a fin de hacer nacer en ellos la máxima del cuidado

${ }^{23}$ Men. 79e7-80d4. Recordemos al respecto las palabras de Agatón, quien en la antesala de su encomio a Éros desenmascara -como más tarde lo hará Alcibíades- la estrategia erótica socrática: "Pretendes hechizarme (pharmáttein), Sócrates, para que me desconcierte, haciéndome creer que domina a la audiencia una gran expectativa ante la idea de que voy a pronunciar un bello discurso" (Smp. 194a5-7). 
del alma y una comprometida disposición hacia el saber:

Así pues, es el alma lo primero que hay que cuidar al máximo, si es que se quiere tener bien a la cabeza y a todo el cuerpo. El alma se trata, mi bendito amigo, con ciertos ensalmos y estos ensalmos son los buenos discursos, y de tales buenos discursos, nace en ella la sensatez" (Chrm. 157a4-5). ${ }^{24}$

Por otro lado, a la luz de lo examinado, cabe preguntarse qué relación guarda la dimensión práctica de la tékhnē de la caza erótica de jóvenes bellos, esbozada en los pasajes platónicos y de Jenofonte relevados, con el saber de carácter teorético (o de tipo eidético-trascendente) que corona el recto amor de los jóvenes pautado en la iniciación erótica de Diotima en el Banquete. A fin de compaginar ambas vertientes del saber erótico de Sócrates, puede suponerse que la tékhnē de la caza erótica de jóvenes bellos constituye el cimiento sobre el que se levanta aquella paideía del deseo erótico sistematizada en el discurso de Diotima, en la medida en que el primer grado de la iniciación erótica (relativo al amor por la belleza de un solo cuerpo a fin de engendrar en él bellos razonamientos, Smp. 210a4-8), implica la áskēsis de dicha tékhnēe. ${ }^{25} \mathrm{Si}$ pensamos, en efecto, en el primer grado del ascenso pautado por Diotima, para enfocar el deseo erótico hacia la belleza de un solo cuerpo es necesario antes hacerlo entrar en la práctica del cortejo a fin de hacerse desear por el joven a fuerza de quererlo, ${ }^{26} \mathrm{y}$ ello puede lograrse a través de la técnica persuasiva de la caza erótica, por cuyo medio el joven se ve magnetizado por la figura socrática

${ }^{24}$ Véase en la misma línea Jenofonte, Mem. II, 6, 10-13. Sobre esta atmósfera erótica montada por Sócrates, cf. F. Rodríguez Adrados, Sociedad, amor y poesía en la Grecia antigua, Madrid, Alianza, 1995, pp. 44-51; у НАдот, Elogio..., p. 63, quien resume al respecto: "En Sócrates los jóvenes encuentran, por tanto, el camino hacia su propia perfección".

${ }^{25}$ Para la relación entre el deseo sexual y el deseo de saber, cf. especialmente Dover, Greek..., p. 12; G. Vlastos, "Sex in Platonic Love", in Platonic Studies, Princeton, Princeton University Press, 1973, p. 40; M. Nussbaum, La fragilidad de bien, Madrid, Visor, 1995, p. 258: "Es fácil descubrir paralelismos estructurales entre deseo sexual y el deseo de sabiduría. Ambos se dirigen a objetos del mundo y pretenden algún tipo de posesión. En los dos casos, la aprehensión del objeto deseado proporciona saciedad y una cesación temporal del deseo [...]. Ambos deseos pueden ser excitados por la belleza y el bien y buscan comprender su naturaleza. Ambos reverencian el objeto como entidad completa y separada y, sin embargo, tienen por fin su incorporación"; y M. CAJTHAmL, "On the Relationship Between Pederasty and Plato's Philosophical Theory of Love", in A. Havlíček - M. Cajthaml (eds.), Plato's Symposium: Proceedings of the Fifth Symposium Platonicum Pragense, Prague, Oikoymenh, 2007, p. 121, quien se ocupa de relevar de manera detallada las diferencias y semejanzas entre el amor pederástico y la teoría filosófica del amor platónico. ${ }^{26}$ Cf. Jenofonte, Mem. II, 6, 28-30. 
que atrae no tanto por sus dotes físicos como por su capacidad dialógica de resistencia frente al encanto de los jóvenes. Platón es así consecuente con un motivo recurrente en su plataforma conceptual, a saber: que para alcanzar el saber eidético-trascendente lo sensible-inmanente opera como primer estímulo necesario -pensemos al respecto en la teoría de la reminiscencia desarrollada en Menón y Fedón-, que, en el caso puntual del ascenso pautado por Diotima, se traduce en una áskēsis erótica en pos de la belleza sensible de un joven (o cuerpo bello), para desde allí despegarse gradualmente hacia la aprehensión de la Idea de belleza. La dimensión práctica del saber comprometido en la tékhne de la caza erótica vendría a representar entonces la antesala necesaria de la dimensión teorética implicada en el saber erótico de tipo eidético-trascendente ubicado en el sexto y último grado de la iniciación erótica. Tal compaginación permitiría iluminar y dar cuenta de la doble vertiente (práctica y teorética) del saber erótico que Sócrates confiesa tener al comienzo del Banquete.

\section{TitLe. Practical dimension of Socrates' erotic knowledge}

ABSTRACT. What is it that Socrates exactly knows about love? What dimensions are involved in this type of erotic knowledge? How does someone introduce themselves in connection with love, who at the end of his speech says that he especially exercises in love affairs and urges others to do the same (Smp. 212b5-7)? These are the topics that I am going to develop in this article, starting from a number of passages taken from the early and transitional platonic dialogues and from Xenophon's Memorabilia and Symposium; passages through which I will examine, on the one hand, the practical dimension (áskésis) involved in the socratic erotic knowledge, and on the other hand, its relationship with the theoretical dimension of this knowledge, when aimed to the Form of beauty in Symposium.

KEYwords. Éros; knowledge; áskēsis; young; beauty. 